\title{
OPTIMIZATION OF DRILLING PARAMETERS DURING MACHINING OF Al-Mg-Si ALLOYS BY TAGUCHI METHOD COUPLED WITH GREY RELATIONAL ANALYSIS AND VALIDATED BY FEA BASED DEFORM - 3D
}

\author{
${ }^{1 *}$ REDDY Sreenivasulu, ${ }^{2}$ CHALAMALASETTI SrinivasaRao \\ ${ }^{1}$ Department of Mechanical Engineering, R.V.R \& J. C. College of Engineering (A), Chowdavaram, \\ Guntur, Andhra Pradesh, India, e-mail: rslu1431@gmail.com \\ ${ }^{2}$ Department of Mechanical Engineering, College of Engineering (A), \\ Andhra University, Vishakhapatnam, AndhraPradesh, India
}

\begin{abstract}
In the present work to validate the experimental results as per Taguchi based grey relational analysis by considering $\mathrm{L}_{27}$ orthogonal array corresponding to five factors with three levels and obtained optimal combination of input parameters to minimize the output responses during drilling process which is most important finishing operation required in the structural assembly works where we found application of $\mathrm{Al}-\mathrm{Mg}-\mathrm{Si}$ alloys, Deform-3D software is implemented and found good feasibility with that of experimental results.
\end{abstract}

KEYWORDS: Grey based Taguchi Approach, Thrust force, Torque, Al-Mg-Si alloy, Deform-3D

\section{Introduction}

Without any one of the machining process there is no component in the core industry in all engineering fields, it is real fact. Metal removal processes such as turning process with single point cutting tool, milling process with multi point cutter and hole making process either drilling or boring operations are primarily required to alter the parts from raw material to required final shape. Some of the previous researchers mentioned that $30 \%$ of total fabrication industries utilized by hole making processes with different sizes of twist drill bits [1]. At present, importance of making holes on human bones and other allied parts found in biomedical engineering areas especially in orthopedics, so that research in this area still exists even though it is primary machining process $[2,3]$. It is found that, numerous holes required in the case of auto and aero structural (roof) assembly purposes either with bolt and nuts (temporary joint) or riveted joints (permanent) there drilling operation takes vital role. The mechanism during drilling is very complex because, it is a function of factors influenced on stationary parent material and rotating drill bit. But, in view of reliability of assembly process most of the authors in this area chosen few important parameters which are influenced directly or indirectly on formation of burr, which is a main problem faced while assemble the components after drilling is over on required positions on a parent materials where we assemble them, which are found that drill tool wear, drill thrust and torque generated between drill tool and work piece material because formation of hole on a material is due to shearing of material and surface quality also one of the important parameter which indicates quality of assembled part[4]. Selection of suitable machining conditions often complex task to create a good quality hole, for that different strategies are applied by different researchers in different manner, but the main motive of such strategies are effective drilling only. The choice of appropriate manufacturing conditions and methods are required for an efficient drilling 
process. Therefore, the choice of machining conditions while drilling is a significant role, which helps to decrease the drill tool vibrations, heat produced thrust and torque exerted during drilling operation and increase surface quality. This is possible only by suitable selection of input and output factors with respect to geometry of drill bit as well as limitations of machine. Apart from machining conditions, methods to apply to analyze the level of influence of input parameters over output responses also equal importance. One of the technique even though it is old still it appears in the literature is statistical technique, helped to determine influence of such factors without damage the others[5], Taguchi based selection of experiments reduce the repetition of machining operations in shop floor and provide optimized results in the selection of cutting parameters during various metal removal processes[6]. By conducting of continuous experiments to finalize better machining conditions, requires more investment which are not profitable especially for MSME (Micro, Small\& Medium Enterprises) industries, to avoid that computer software based simulations provide good idea to select appropriate initial conditions without experimentation causes reduce investment also helps to alter the simulations easily if particular strategy is failed to satisfy the customer requirement. In this connection, finite element analysis (FEA) based 3D solid modelling and analysis software developed for metal removal as well as metal forming processes [7, 8]. Present modern manufacturing industrial engineers gained more knowledge towards particular machining operation even though it is more complex by adopting computer simulations related to their task. In this paper, numerical simulation software called as deform-3D was implemented to validate the results of experimental models.

\section{Experimentation}

In the present experimental investigation, the parameter optimization of drilling of Al-MgSi alloys with multi-response criteria based on the Taguchi orthogonal array with the grey relational analysis was considered. Twenty seven experimental runs based on $\mathrm{L}_{27}$ orthogonal array of Taguchi method is used to perform holes on Al-Mg-Si alloy work pieces (alloy composition provided in table 1). The input drilling parameters such as spindle speed, feed rate, drill diameter, point angle and clearance angle are optimized with a consideration of multiple performance characteristics, (output responses) namely thrust force and torque are assessed. A grey relational grade obtained from the grey relational analysis is used to solve the multiple performance characteristics in drilling process. Additionally, the analysis of variance (ANOVA) is applied to identify the most significant input parameter. Finally, confirmation tests are performed to make a comparison between the experimental results and developed models.

Table 1 Chemical composition of Al-Mg-Si alloy

\begin{tabular}{|c|c|c|c|c|c|c|c|}
\hline Element & Silicon & Copper & Zinc & Iron & Manganese & Magnesium & Aluminium \\
\hline$\% \mathrm{Wt}$ & 0.63 & 0.096 & 0.091 & 0.466 & 0.179 & 0.53 & Remaining \\
\hline
\end{tabular}

\subsection{Tools and Equipment}

In this study, drilled holes are performed on a rectangular cross section work pieces made up of with Al-Mg-Si alloy using radial drilling machine (Make: Siddapura Machine Tools, Gujarat, INDIA) according to Taguchi method. Tool and cutter grinding machine helped to modify the clearance and point angles as per required levels of input parameters. Initially, different size of twist drill bits purchased with a 45 degrees helix angle, 4 degrees clearance angle and 118 degrees point angles then change their angles. A drill tool dynamometer (Kistler type9272 model) used to measure thrust and torque exhibited during performing a hole on a material with a rotary drill tool, and the signal is processed to the computer by 
connecting 5070 multichannel signal electronic equipment to obtain response data (shown in Fig.1).

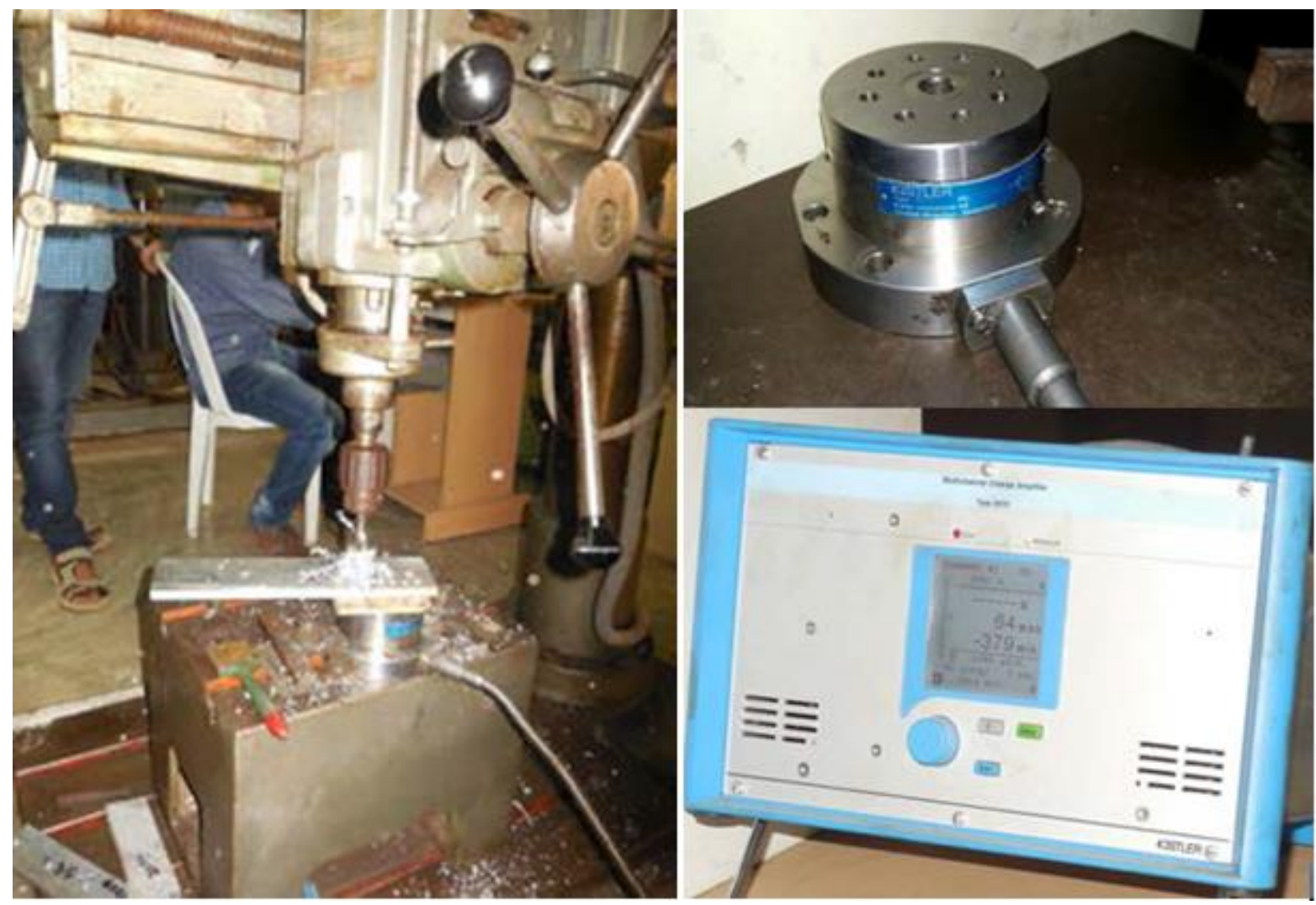

Fig. 1 Pillar radial drilling machine with Dynamometer setup

\subsection{Design of Experiments based on Taguchi Method}

The concept of the Taguchi method is that the parameter design is performed to cut back the sources of variation on the standard characteristics of product, and reach a target of process robustness. It utilizes the orthogonal arrays from experimental design theory to review an outsized number of variables with small number of experiments. Further, the conclusions drawn from small scale experiments are valid over the complete experimental region spanned by control parameters and their level settings [9-14]. The preference of orthogonal array is anxious with the full degree of freedom of process parameters. Within the present work, total degree of freedom related to five input parameters is adequate to 10 (5x2). The degree of freedom for the orthogonal array should be greater than or a minimum of capable that of the input process parameters. There by, a $\mathrm{L}_{27}$ orthogonal array having degree of freedom capable (27-1) 26 has been considered, which is employed to optimize the drilling parameters for minimum burr formation mainly. The chosen input parameters and their levels as per Taguchi's design plan are depicted as in table 2

Table 2 Level of input factors selected for experimentation

\begin{tabular}{|c|c|l|l|l|l|}
\hline \multirow{2}{*}{$\begin{array}{l}\text { Levels } \\
\text { of } \\
\text { input } \\
\text { factors }\end{array}$} & \multicolumn{6}{|c|}{\begin{tabular}{l} 
Input Factors \\
\cline { 2 - 6 }
\end{tabular}} & $\begin{array}{l}\text { Spindle } \\
\text { (rpm) A }\end{array}$ & $\begin{array}{l}\text { Feed } \\
\text { Rate } \\
(\mathrm{mm} / \mathrm{min}) \mathrm{B}\end{array}$ & $\begin{array}{l}\text { Drill } \\
\text { Diameter } \\
(\mathrm{mm}) \mathrm{C}\end{array}$ & $\begin{array}{l}\text { Point } \\
\text { Angle } \\
\text { D }\end{array}$ & $\begin{array}{l}\text { Clearance } \\
\text { Angle } \\
\text { E }\end{array}$ \\
\hline 1 & 465 & 18 & 8 & $100^{0}$ & $4^{0}$ \\
\hline 2 & 695 & 20 & 10 & $110^{0}$ & $6^{0}$ \\
\hline 3 & 795 & 26 & 12 & $118^{0}$ & $8^{0}$ \\
\hline
\end{tabular}




\subsection{Grey based Taguchi approach}

The integrated gray based mostly taguchi technique combine's blessings of each gray relative analysis and taguchi technique. This technique was with success applied to optimize the multi response of sophisticated issues in producing processes. Moreover, analysis of variance is performed to work out that method parameters area unit statistically vital. The integrated gray based mostly taguchi technique combines the algorithmic rule of taguchi technique and grey relative analysis to figure out method parameters for multiple responses. The block diagram of this method was found in Fig. 2

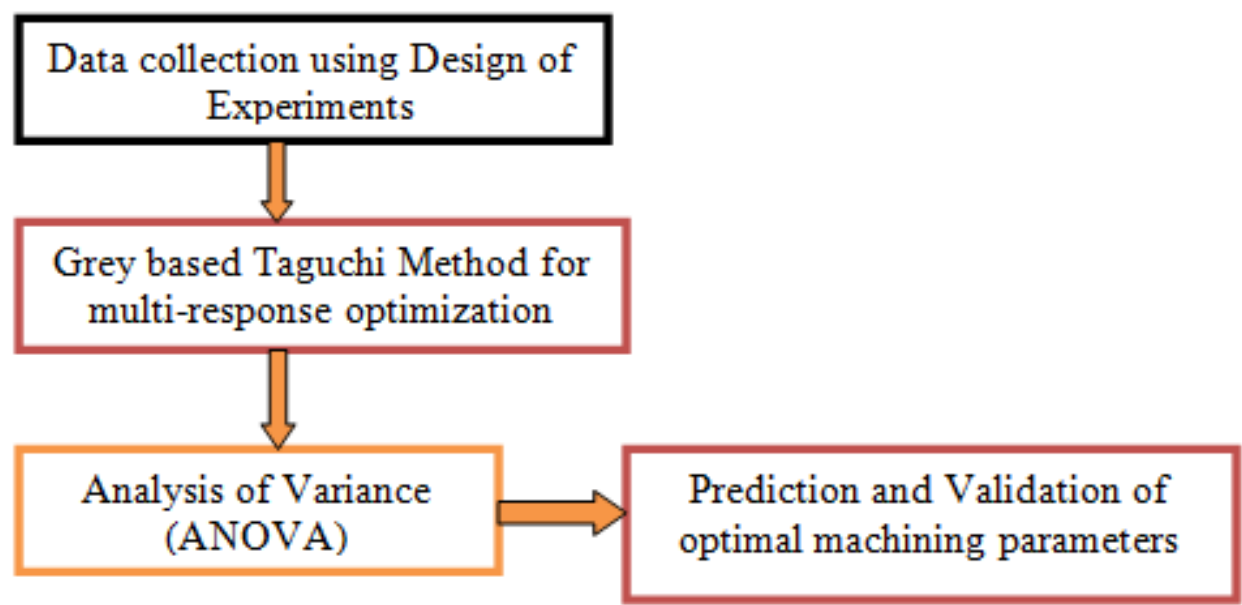

Fig. 2 Block diagram shows Grey based Taguchi method

\subsubsection{Data Acquisition}

The output parameters recorded for each of the experiments are the Thrust force and Torque. A Kistler type 9272, Kistler four components ( $\mathrm{F}_{\mathrm{X}}, \mathrm{F}_{\mathrm{Y}}, \mathrm{F}_{\mathrm{Z}}$ and $\mathrm{Mz}$ ) dynamometer is used to measure the responses and the signal is processed to the computer by a type 5070 multichannel signal amplifier. Table 3 shows the data as recorded by the Kistler dynamometer during the drilling of Al-Mg-Si alloy work piece for RMS values of thrust force and torque and these values are directly utilized in further tables.

Table $3 \mathrm{~L}_{27}$ orthogonal array and measured output responses

\begin{tabular}{|l|l|l|l|l|l|l|l|}
\hline Trials & A & B & C & D & E & Fz & $\mathrm{Mz}$ \\
\hline 1 & 465 & 18 & 8 & 100 & 4 & 178 & 268 \\
\hline 2 & 465 & 18 & 8 & 100 & 6 & 166 & 254 \\
\hline 3 & 465 & 18 & 8 & 100 & 8 & 161 & 248 \\
\hline 4 & 465 & 20 & 10 & 110 & 4 & 208 & 287 \\
\hline 5 & 465 & 20 & 10 & 110 & 6 & 168 & 258 \\
\hline 6 & 465 & 20 & 10 & 110 & 8 & 197 & 264 \\
\hline 7 & 465 & 26 & 12 & 118 & 4 & 149 & 238 \\
\hline 8 & 465 & 26 & 12 & 118 & 6 & 241 & 347 \\
\hline 9 & 465 & 26 & 12 & 118 & 8 & 184 & 242 \\
\hline 10 & 695 & 18 & 10 & 118 & 4 & 243 & 312 \\
\hline 11 & 695 & 18 & 10 & 118 & 6 & 159 & 222 \\
\hline 12 & 695 & 18 & 10 & 118 & 8 & 218 & 328 \\
\hline 13 & 695 & 20 & 12 & 100 & 4 & 156 & 228 \\
\hline 14 & 695 & 20 & 12 & 100 & 6 & 151 & 200 \\
\hline 15 & 695 & 20 & 12 & 100 & 8 & 164 & 187 \\
\hline 16 & 695 & 26 & 8 & 110 & 4 & 228 & 324 \\
\hline 17 & 695 & 26 & 8 & 110 & 6 & 147 & 219 \\
\hline 18 & 695 & 26 & 8 & 110 & 8 & 220 & 244 \\
\hline
\end{tabular}




\begin{tabular}{|l|l|l|l|l|l|l|l|}
\hline 19 & 795 & 18 & 12 & 110 & 4 & 189 & 214 \\
\hline 20 & 795 & 18 & 12 & 110 & 6 & 191 & 209 \\
\hline 21 & 795 & 18 & 12 & 110 & 8 & 233 & 264 \\
\hline 22 & 795 & 20 & 8 & 118 & 4 & 212 & 254 \\
\hline 23 & 795 & 20 & 8 & 118 & 6 & 242 & 229 \\
\hline 24 & 795 & 20 & 8 & 118 & 8 & 163 & 196 \\
\hline 25 & 795 & 26 & 10 & 100 & 4 & 164 & 188 \\
\hline 26 & 795 & 26 & 10 & 100 & 6 & 169 & 223 \\
\hline 27 & 795 & 26 & 10 & 100 & 8 & 198 & 241 \\
\hline
\end{tabular}

\subsection{Grey relational analysis}

The grey relational analysis supported the grey system theory is accustomed solve the complicated interrelationships among the multiple responses effectively. In a grey system theory developed by Deng and implemented in industrial engineering in the beginning later applied to all engineering fields especially where lack of information existed or where something is known and something is unknown. In a grey system theory, black represents unknown information and white represents known, which includes a level of data between black and white. This analysis is will not represent the grade of correlation between two sequences in order that the gap of two factors will be measured discretely. Within the case when experiments are ambiguous or when the scientific method cannot provide exact solution, grey analysis helps to make amends for the shortcoming in simple regression. Grey relation analysis is an efficient means of analyzing the link between sequences with less data and might analyze many factors that may overcome the disadvantages of statistical procedure it's applied in optimization of assorted machining operations with multipleresponses [15].

\subsubsection{Data Normalization}

Data normalization is generally required since the range and unit in one data sequence may differ from the others. It is also necessary when the sequence scatter range is too bulky, or when the directions of the target in the set of diversified sequences. Normalization of data is a means of converting the original sequence to a comparable sequence. There are various methodologies available for normalization process of data obtained from the experiments depending upon the sequential data in the case of grey system theory. If the target value of primary sequence is infinite, then it has a attribute of the "higher is better". Then the original sequence normalization can be processed as follows:

$$
x_{i}^{*}(k)=\frac{x_{i}^{0}(k)-\min x_{i}^{0}(k)}{\max x_{i}^{0}(k)-\min x_{i}^{0}(k)}
$$

When the "lower is better" is a characteristic of the original sequence, then the original sequence should be normalized as follows:

$$
x_{i}^{*}(k)=\frac{\left[\max x_{i}^{0}(k)-x_{i}^{0}(k)\right]}{\left[\max x_{i}^{0}(k)-\min x_{i}^{0}(k)\right]}
$$

However, if there is a definite target value (desired value) to be achieved, the original sequence will be normalized in form or, the original sequence can be simply normalized by the most basic methodology, i.e. let the values of original sequence be divided by the first value of the sequence: 


$$
\begin{gathered}
x_{i}^{*}(k)=1-\frac{\left|x_{i}^{0}(k)-x^{0}\right|}{\max x_{i}^{0}(k)-x^{0}} \\
x_{i}^{*}(k)=\frac{x_{i}^{0}(k)}{x_{i}^{0}(1)}
\end{gathered}
$$

Where, $i=1 \ldots m ; k=1 \ldots n$. ' $m$ ' is the number of experimental runs and ' $n$ ' is the number of factors selected to do experiments. $\mathrm{X}^{0}{ }_{\mathrm{i}}(\mathrm{k})$ denotes the original sequence, $\mathrm{x}^{*}{ }_{\mathrm{i}}(\mathrm{k})$ the sequence after the normalization of data, $\max x^{0} i(k)$ the largest value of $x^{0}{ }_{i}(k), \min x^{0} i(k)$ the smallest value of $x^{0} i(k)$ and $x^{0}$ is the desired value. For data normalization in the grey relational analysis, all the measured output values are taken as the "lower is better" (LB). Let the results of 27 trials be the comparability sequences $x^{0} i(k), i=1-27, k=1$. All the sequences after normalization using Eq. 2 comparability sequence are obtained and presented in table 3. After completion of normalization of response, the grey coefficient $\xi_{i}(k)$ for the $\mathrm{k}^{\text {th }}$ performance characteristics in the $\mathrm{i}^{\text {th }}$ experiment can be expressed as:

$$
\xi_{i}(k)=\frac{\Delta_{\min }+\xi \Delta_{\max }}{\Delta_{0 i}(k)+\xi \Delta_{\max }}
$$

Table 4 Data acquisition from grey relational analysis

\begin{tabular}{|l|l|l|l|l|l|}
\hline \multirow{2}{*}{ Exp.No. } & \multicolumn{2}{|l|}{$\begin{array}{l}\text { Comparability } \\
\text { Sequence }\end{array}$} & \multicolumn{2}{l|}{$\begin{array}{l}\text { Grey relational } \\
\text { coefficients }\end{array}$} & $\begin{array}{l}\text { Grey } \\
\text { relational } \\
\text { grades }\end{array}$ \\
\cline { 2 - 6 } & Fz & $\mathrm{Mz}$ & $\mathrm{Fz}$ & $\mathrm{Mz}$ & \\
\hline 1 & 0.6770 & 0.4937 & 0.6789 & 0.4912 & 0.5850 \\
\hline 2 & 0.8021 & 0.5812 & 0.7164 & 0.5425 & 0.6294 \\
\hline 3 & 0.6458 & 0.2812 & 0.5853 & 0.4139 & 0.4996 \\
\hline 4 & 0.3646 & 0.3750 & 0.4403 & 0.4410 & 0.4406 \\
\hline 5 & 0.7812 & 0.5562 & 0.6956 & 0.5211 & 0.6083 \\
\hline 6 & 0.4792 & 0.5187 & 0.4898 & 0.5001 & 0.4949 \\
\hline 7 & 0.9791 & 0.8687 & 0.9598 & 0.7912 & 0.8755 \\
\hline 8 & 0.0312 & 0.0000 & 0.3404 & 0.3385 & 0.3394 \\
\hline 9 & 0.6146 & 0.6562 & 0.5647 & 0.5957 & 0.5802 \\
\hline 10 & 0.0000 & 0.1812 & 0.3333 & 0.3787 & 0.3561 \\
\hline 11 & 0.8750 & 0.7812 & 0.8000 & 0.6974 & 0.7487 \\
\hline 12 & 0.2604 & 0.1187 & 0.4033 & 0.3627 & 0.3831 \\
\hline 13 & 0.9062 & 0.7437 & 0.8420 & 0.6699 & 0.7559 \\
\hline 14 & 0.9583 & 0.9187 & 0.9230 & 0.8618 & 0.8924 \\
\hline 15 & 0.8229 & 1.0000 & 0.7384 & 1.0000 & 0.8692 \\
\hline 16 & 0.1562 & 0.1437 & 0.3721 & 0.3633 & 0.3677 \\
\hline 17 & 1.0000 & 0.8000 & 1.0000 & 0.7149 & 0.8574 \\
\hline 18 & 0.2396 & 0.6437 & 0.3966 & 0.5879 & 0.4922 \\
\hline 19 & 0.5625 & 0.8312 & 0.5333 & 0.7410 & 0.6371 \\
\hline 20 & 0.5416 & 0.8625 & 0.5217 & 0.7892 & 0.6554 \\
\hline 21 & 0.1041 & 0.5187 & 0.3582 & 0.5001 & 0.4291 \\
\hline 22 & 0.3229 & 0.5812 & 0.4247 & 0.5404 & 0.4825 \\
\hline 23 & 0.0104 & 0.7375 & 0.3356 & 0.6507 & 0.4931 \\
\hline 24 & 0.8333 & 0.9437 & 0.7499 & 0.8963 & 0.8231 \\
\hline 25 & 0.9489 & 0.9937 & 0.9156 & 0.9827 & 0.9491 \\
\hline 26 & 0.7708 & 0.7750 & 0.6856 & 0.6882 & 0.6869 \\
\hline 27 & 0.4687 & 0.6625 & 0.4848 & 0.5911 & 0.5379 \\
\hline & & & & & \\
\hline
\end{tabular}

Where, $\Delta_{\mathrm{oi}}$ is the divergence run of the reference series and the comparability order. The distinguishing coefficient $\zeta$ can be replaced in the Eq. 5 to get the grey relational coefficient. 
If all the drilling parameters are of equal weightage, then $\zeta$ is 0.5 . The grey relational coefficients and its grade values for each trial of drilling experiment as per $\mathrm{L}_{27}$ orthogonal array were determined by equation 5 (depicted in table 4 ).

According to the design of experiments based on Taguchi and grey relational analysis, it is observed from table 4 and that combination of setting of parameters during drilling has been found that $25^{\text {th }}$ trial of experiment has the highest grey relational grade. From table 5 , it is observed that A1B3C3D1E1 is the order of priority of the controllable parameters to achieve the multi-performance characteristics in the drilling of Al-Mg-Si alloy and also observed that point angle, clearance angle and drill diameter (relates to geometry of drill tool) are showing highest grey relational grades which indicates the moderate influence out of five factors considered at the beginning of experiments.

Table 5 Response table for average grey relational grade

\begin{tabular}{|l|l|l|l|}
\hline \multirow{2}{*}{$\begin{array}{l}\text { Drilling } \\
\text { input parameters }\end{array}$} & \multicolumn{3}{|c|}{ Average grey relational grade by factor level } \\
\cline { 2 - 4 } & Level 1 & Level 2 & Level 3 \\
\hline Spindle Speed, A & 0.5975 & 0.5688 & 0.5666 \\
\hline Feed rate, B & 0.5763 & 0.5737 & 0.5802 \\
\hline Drill diameter, C & 0.572 & 0.5554 & 0.6053 \\
\hline Point angle, D & 0.6406 & 0.5461 & 0.5461 \\
\hline Clearance angle, E & 0.6062 & 0.5868 & 0.5398 \\
\hline
\end{tabular}

After attaining the optimal setting of combination of machining characteristics corresponding to the highest grey relational grade, then found the variation of each response with inputs using analysis of variance.

\section{Analysis of Variance (ANOVA)}

Most of the researchers utilized this technique to categorize the crucial effects of the input factors over the responses recorded during machining using minitab@17 software. ANOVA test was conducted for individual responses measured with well calibrated apparatus during drilling operation which is done by taking grey relational grades as inputs then process the data and depicted in table $6 \& 7$.

Table 6 Results of ANOVA for Thrust Force $\left(\mathrm{F}_{\mathrm{Z}}\right)$

\begin{tabular}{|l|l|l|l|l|l|l|}
\hline $\begin{array}{l}\text { Parameter } \\
\text { Symbol }\end{array}$ & $\begin{array}{l}\text { Input } \\
\text { Parameter }\end{array}$ & DO F & SS & MS & F & \\
\hline A & Spindle Speed & 2 & 81656 & 40828 & $5.82^{*}$ & significant \\
\hline B & Feed Rate & 2 & 51917 & 25958 & $3.7^{*}$ & significant \\
\hline C & Drill diameter & 2 & 30921 & 15460 & 2.20 & Insignificant \\
\hline D & Point Angle & 2 & 35872 & 17936 & 2.55 & Insignificant \\
\hline E & Clearance Angle & 2 & 65352 & 32676 & $6.795^{*}$ & significant \\
\hline Error & & 16 & 14032 & 7016 & & \\
\hline Total & & 26 & 265718 & & & \\
\hline
\end{tabular}

Table 7 Results of ANOVA for Torque $\left(\mathrm{M}_{\mathrm{Z}}\right)$

\begin{tabular}{|l|l|l|l|l|l|l|}
\hline $\begin{array}{l}\text { Parameter } \\
\text { Symbol }\end{array}$ & $\begin{array}{l}\text { Input } \\
\text { Parameter }\end{array}$ & DO F & SS & MS & F & \\
\hline A & Spindle Speed & 2 & 3.1019 & 155095 & $4.74^{*}$ & significant \\
\hline B & Feed Rate & 2 & 2.2025 & 1.10125 & 3.36 & Insignificant \\
\hline C & Drill diameter & 2 & 2.8052 & 1.4026 & $4.28^{*}$ & significant \\
\hline D & Point Angle & 2 & 3.6106 & 1.80539 & $5.52^{*}$ & significant \\
\hline E & Clearance Angle & 2 & 2.1244 & 1.06221 & 3.24 & Insignificant \\
\hline Error & & 16 & 5.2343 & 0.32714 & & \\
\hline Total & & 26 & 13.8446 & & & \\
\hline
\end{tabular}




\subsection{Main Effects plots of Data Means of Output Responses}

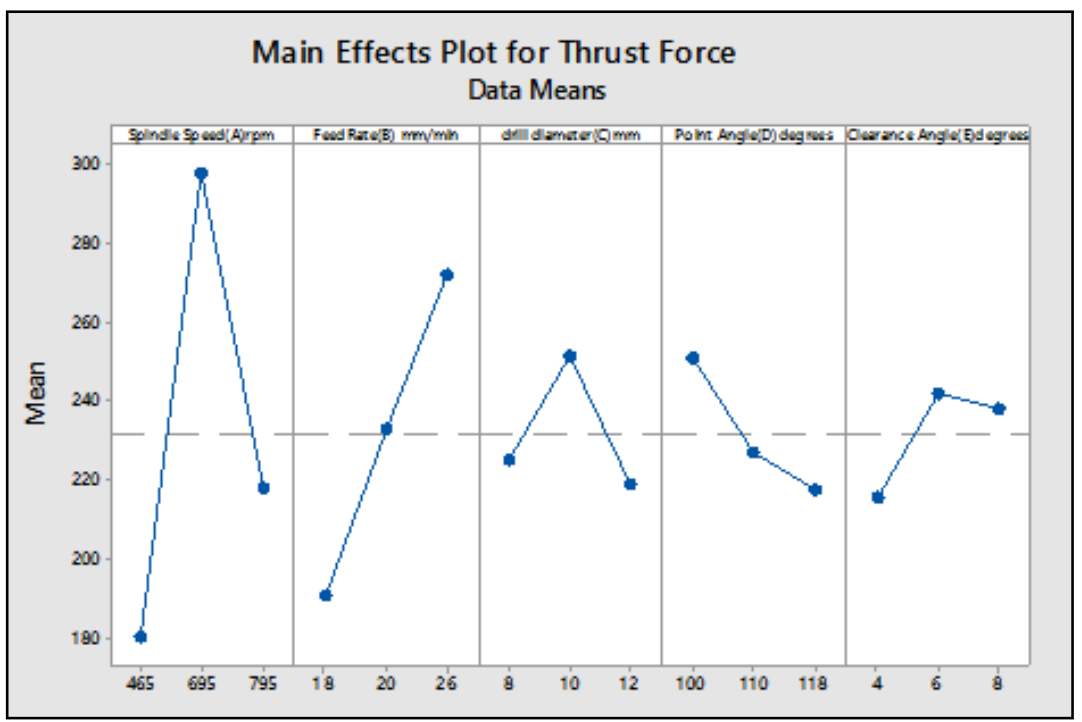

Fig. 3 Main effects plot for Thrust force

Main effects plots are obtained with same software tool mentioned above for data means of output responses from that decision has been taken on optimal combination of drilling parameters to attain optimal responses. The analysis of means is used to identify the optimal process parameter settings by estimating the main effect of each parameter, which is presented in the main effect plot diagrams. Using minitab@17 software, the main effect plots for data means of output responses are identified through ANOM. From these plots analyze the setting of optimal process parameters to attain the multiple performance characteristics of outputs which are measured in the experimentation. The following are the conclusions drawn from ANOM results for the responses of thrust force and torque. The main effects plot shown in fig. 3 for thrust force reveal that the setting of input parameters are A2B3C2D1E2 indicates $695 \mathrm{rpm}, 26 \mathrm{~mm} / \mathrm{min}, 10 \mathrm{~mm}, 100^{\circ}$ and $6^{\circ}$ respectively are the optimal setting of parameters to attain the objective for Al-Mg-Si alloy. The main effects plot shown in fig. 4 for torque reveal that the setting of parameters are A1B2C2D2E2 represent $465 \mathrm{rpm}, 20 \mathrm{~mm} / \mathrm{min}, 10$ $\mathrm{mm}, 110^{\circ}$ and $6^{\circ}$ respectively are the optimal setting of input parameters to meet the desired objective for Al-Mg-Si alloy.

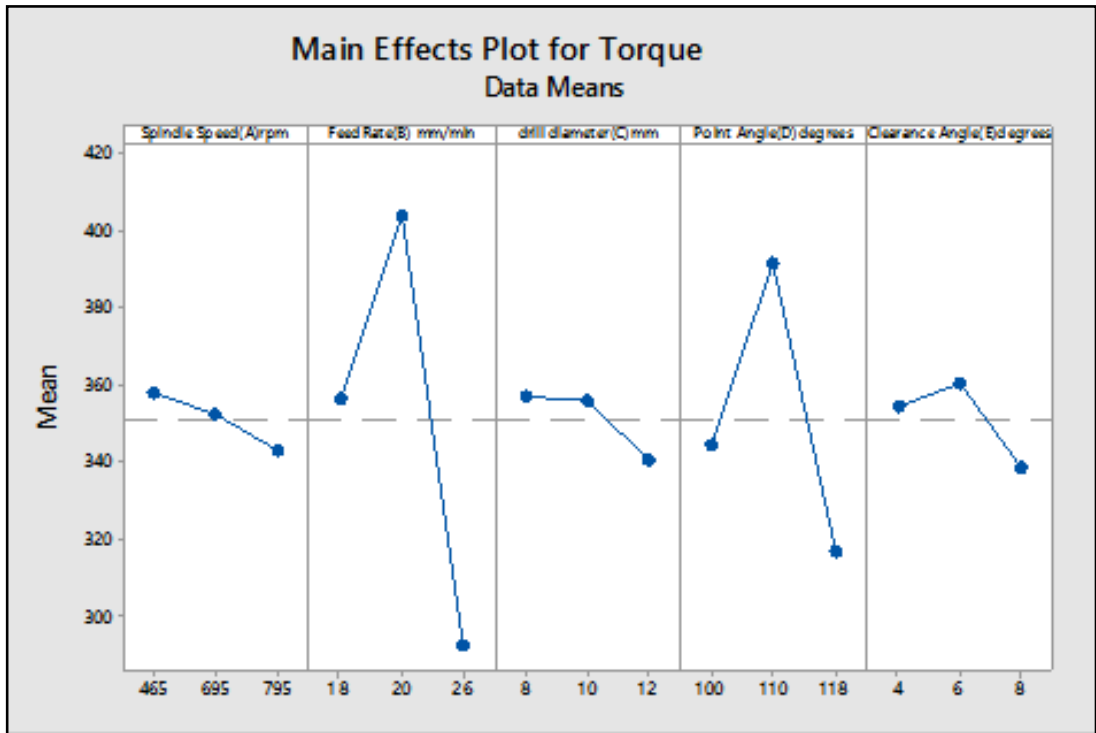

Fig. 4 Main effects plot for Torque 


\subsection{Confirmation Experiment}

Once the optimal level of machining parameters is selected the final step is to predict and verify the improvement of the performance characteristics using the optimal level of the machining parameters. The estimated response value using the optimum level of the machining parameters can be calculated as,

$$
\hat{\gamma}=\gamma_{m}+\sum_{i=1}^{\lambda}\left((\bar{\gamma})_{j}-\gamma_{m}\right)
$$

Where ' $\gamma_{\mathrm{m}}$ ' is the total mean of the response value ' $\gamma_{\mathrm{j}}$ ' is the mean of the response value at the optimum level and ' $q$ ' is the number of machining parameters that significantly affect the multiple performance characteristics. Based on Eq. 6, the estimated thrust force and torque values for the optimal machining parameters can be obtained. Table 6 shows the results of the confirmation experiment setting the optimal machining parameters. From table 8 , it is observed that percentage improvement after confirmation test on thrust force $(\mathrm{Fz})$ and torque (Mz) during drilling of Al-Mg-Si alloy using Grey based Taguchi approach obtained as $16.75 \%$ and $1.06 \%$ respectively. To avoid delay of time and reduce cost of experimentation, simulations are suggested by the authors in the literature, because during the experimentation, due to un controllable factors such as environmental, human errors, machine errors and material errors from suppliers etc., causes little bit of variations occurs even standard procedures are applied. To validate the experimental results, simulation using finite element based Deform-3D software is used in the present investigations.

Table 8 Optimal values of individual machining characteristics

\begin{tabular}{|l|l|l|l|l|}
\hline $\begin{array}{l}\text { Drilling Response } \\
\text { characteristics }\end{array}$ & $\begin{array}{l}\text { Optimal } \\
\text { combination of } \\
\text { parameters }\end{array}$ & $\begin{array}{l}\text { Significant } \\
\text { parameters }\end{array}$ & $\begin{array}{l}\text { Predicted } \\
\text { optimum value }\end{array}$ & $\begin{array}{l}\text { Experimental } \\
\text { value }\end{array}$ \\
\hline Thrust force $(\mathrm{Fz}) \mathrm{N}$ & $\mathrm{A}_{2} \mathrm{~B}_{3} \mathrm{C}_{2} \mathrm{D}_{1} \mathrm{E}_{2}$ & $\mathrm{~A}, \mathrm{~B}, \mathrm{E}$ & 197 & 164 \\
\hline Torque $(\mathrm{Mz}) \mathrm{Nmm}$ & $\mathrm{A}_{1} \mathrm{~B}_{2} \mathrm{C}_{1} \mathrm{D}_{2} \mathrm{E}_{2}$ & $\mathrm{~A}, \mathrm{C}, \mathrm{D}$ & 186 & 188 \\
\hline
\end{tabular}

\section{$4 \quad$ Finite element 3D Numerical Modeling}

The FE model was developed by Deform-3D software to predict the thrust and torque around the cutting edge, Lagrangian approach was considered to create a mesh. The work piece was taken as perfectly plastic and the tool is considered as a rigid body. The Deform-3D software uses finite element machining to simulate the hole making process. The work piece was modelled by the Johnson-Cook (JC) material mode (Eq.6). In the present work, Al-Mg-Si alloy was selected as work piece material and its properties are widely estimated in the literature. The parameters of Johnson-Cook model (JC Model) obtained from the literature related to the same material during drilling operation under similar cutting conditions [16-22]. JC model is preferable in a complex manufacturing process which undergoes large variety of alloys and composite materials for comparison of different constitutive models. The original JC constitutive model, i.e. the combined form considering the strain, strain rate and temperature effect on flow stress, can be mathematically expressed with the relation as presented in the following equation

$$
\bar{\sigma}=\left(A^{1}+B^{1}(\varepsilon)^{n}\right)\left(1+C^{1} * \ln \left(\frac{\dot{\bar{\varepsilon}}}{\frac{\dot{\bar{\varepsilon}}}{\varepsilon_{0}}}\right)\right)\left(1-\left(\frac{T-T_{0}}{T_{\text {melt }}-T_{0}}\right)^{m}\right)
$$


where $\bar{\sigma}$ is the flow stress, $\varepsilon$ is the plastic strain, $\dot{\bar{\varepsilon}}$ is the plastic strain rate, $\overline{\overline{\varepsilon_{0}}}$ is the reference plastic strain rate $\left(0.002 \mathrm{~s}^{-1}\right), \mathrm{T}$ is the temperature of the work piece, $\mathrm{T}_{\text {melt }}$ is the melting temperature of the work piece material and $\mathrm{T}_{0}$ be the room temperature $(303 \mathrm{~K})$; material constant $\mathrm{A}^{1}$ is the yield strength, $\mathrm{B}^{1}$ is the hardening modulus, $\mathrm{C}^{1}$ be the strain rate sensitivity, ' $\mathrm{n}$ ' is that the strain-hardening exponent and ' $\mathrm{m}$ ' is that the thermal softening exponent. Although a more realistic simulation model for the machining process should also take the parameters for Al-Mg-Si alloys are $\mathrm{A}^{1}=314 \mathrm{MPa}, \mathrm{B}^{1}=118 \mathrm{MPa}, \mathrm{n}=0.46, \mathrm{C}^{1}=$ $0.003, \mathrm{~m}=1.35, \mathrm{~T}_{\text {melt }}=550 \mathrm{~K}$. The work piece is represented by a cylindrical model of $10 \mathrm{~mm}$ radius, where the twist drill bit is modeled as a rigid body, which rotates at the specified spindle speed. Before start the simulation steps, provide the data regarding flow stress by giving the new values of strain, strain rate and temperature to reflect the material behavior. The magnitude of the material constitutive models has been imported from the material database of Deform-3D; provides stress-strain curves under different plastic deformation conditions which are temperature, strain rate and the curves of thermal expansion coefficient, elastic modulus, poison's ratio, specific heat, thermal conductivity. In the present work, thermo-mechanical properties of Al-Mg-Si alloys are chosen from the material database of Deform-3D software.

Table 9 List of parameters selected during Numerical modeling for Deform-3D

\begin{tabular}{|l|l|l|}
\hline Main Category & Sub Category & Values \\
\hline Cutting Parameters & Cutting speed & $1000 \mathrm{~mm} / \mathrm{sec}$ \\
\hline & Feed rate & $0.5 \mathrm{~mm} / \mathrm{rev}$ \\
\hline & Temperature & $28^{0} \mathrm{C}$ \\
\hline & Convection coefficient & $0.02 \mathrm{~N} / \mathrm{sec} / \mathrm{mm} /{ }^{0} \mathrm{C}$ \\
\hline \multicolumn{2}{|l|}{} \\
\hline & Shear friction factor & 0.6 \\
\hline & Heat transfer coefficient & $45 \mathrm{~N} / \mathrm{sec} / \mathrm{mm} /{ }^{0} \mathrm{C}$ \\
\hline Drill geometry parameters & $10 \mathrm{~mm}$ \\
\hline & Drill bit diameters & 2 \\
\hline & No. of flutes & $5 \mathrm{~mm}$ \\
\hline & Drill radius & $1.8 \mathrm{~mm}$ \\
\hline & Web thickness & $45^{0}$ \\
\hline & Helix angle & $118^{0}$ \\
\hline & Point angle & $6^{0}$ \\
\hline & Clearance angle \\
\hline Work piece geometry parameters & $30 \mathrm{~mm}$ \\
\hline & Diameter & $10 \mathrm{~mm}$ \\
\hline & thickness \\
\hline Simulations steps & \multicolumn{2}{|l}{} \\
\hline & No. of simulation steps & 10000 \\
\hline & Step increment & 25 \\
\hline & Drill depth & $2.5 \mathrm{~mm}$ \\
\hline
\end{tabular}

In finite element modeling, 100000 elements of tetrahedron shape with 20000 nodes were considered for work piece material assumed as plastic with cylindrical shape of $10 \mathrm{~mm}$ diameter and 30000 (tetrahedron) elements with 20000 ports chosen for drill which is assumed to be solid body which rotates with a specified rotational speed (shown in figure.5). The heat, which is actually generated by pressure exerted between work piece and drill during 
formation of hole by shearing the work material in downward feed, is to be transferred to the environment via heat conduction mode. In the present work, to validate the experimental results a Simulation of drilling of Al-Mg-Si alloy using Deform-3D is applied and data as acquired viz., temperature, thrust force and torque.

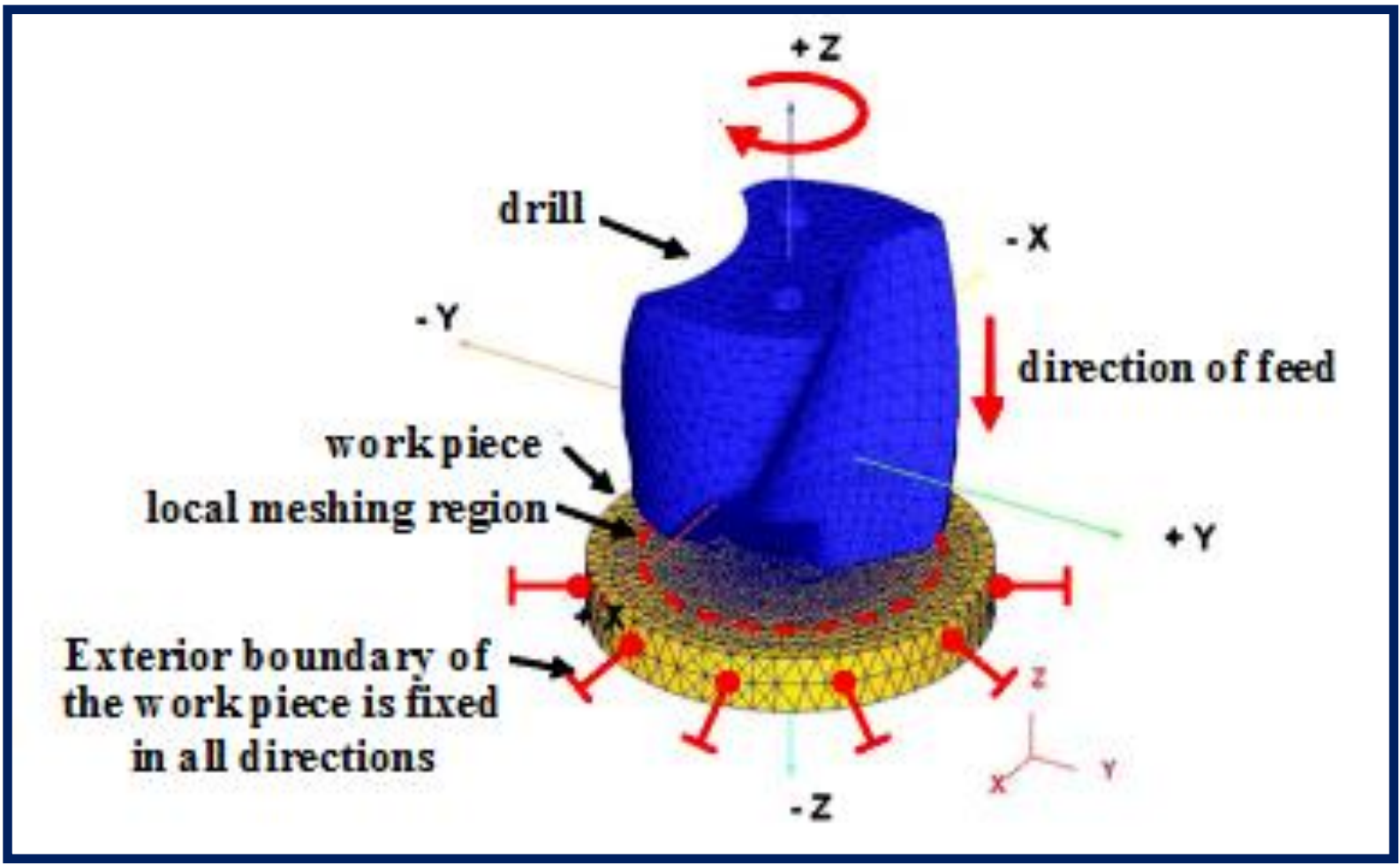

Fig.5 setting of boundary conditions for work piece and drill

From figure 6, it is revealed that load (Thrust Force) prediction during drilling of Al-Mg-Si alloy at the simulation step 2886 interval is obtained as the maximum of 321(RMS value of Thrust force) $\mathrm{N}$ and maximum torque is obtained as 318 (RMS value of Torque) $\mathrm{N} \mathrm{mm}$ at the same step interval.

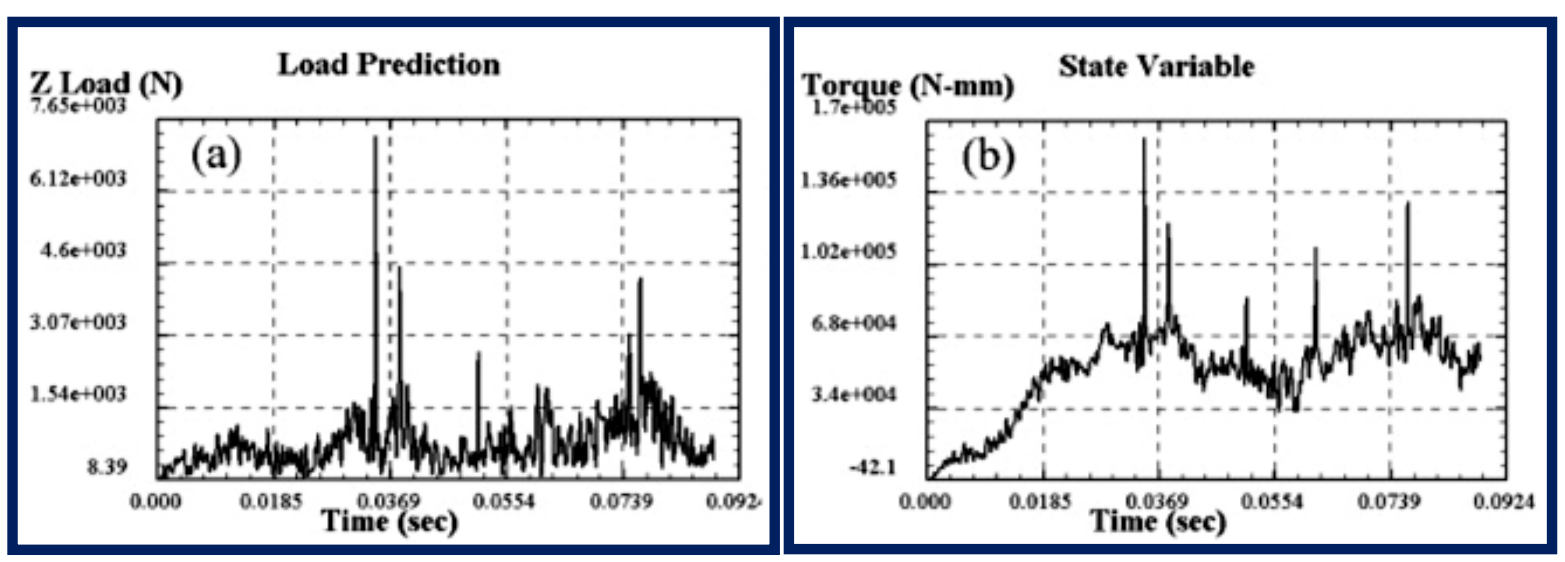

Fig. 6 Thrust force and Torque during drilling

\subsubsection{Heat distribution during drilling}

At the step interval of 2886 generation of heat occurs between tool and work piece in the shear deformation zone, leads to enhance the temperature in the range of $28^{\circ} \mathrm{C}$ to $304^{\circ} \mathrm{C}$ during drilling of Al-Mg-Si alloy, depicted in Fig.7. 


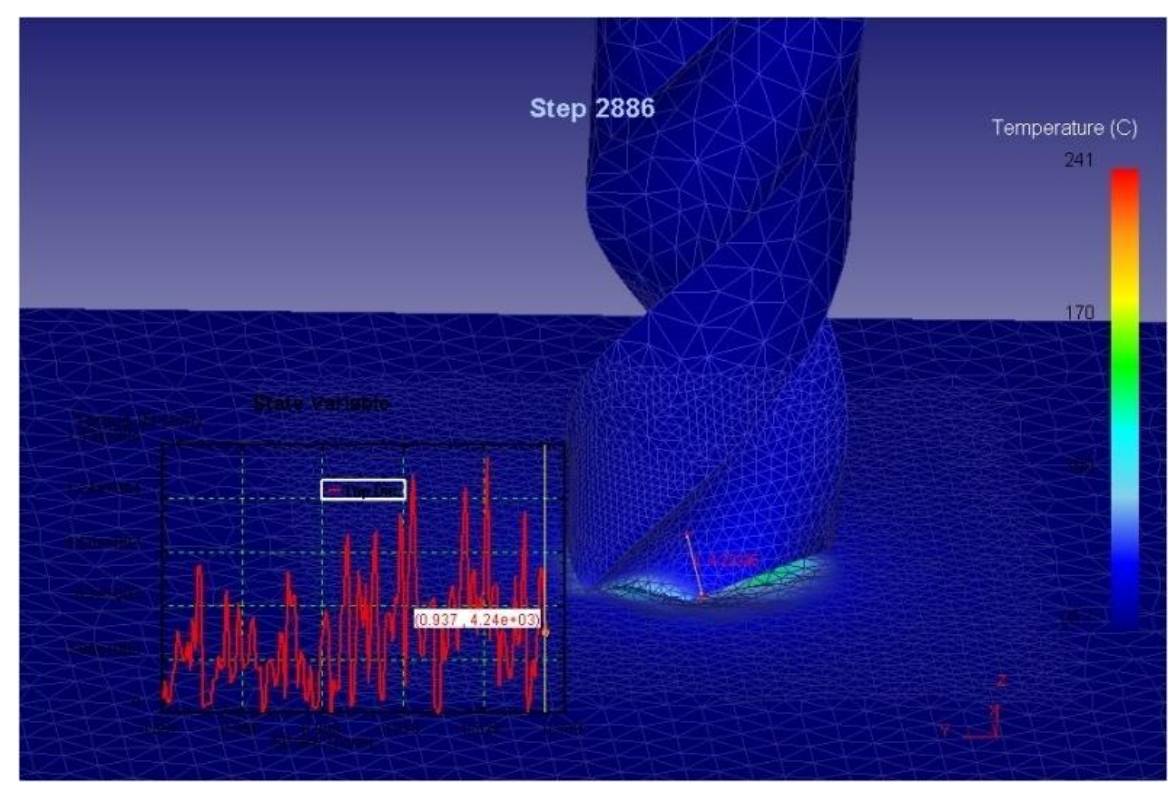

Fig. 7 Heat generation due to shearing of material while making a hole

From the simulation results, it is concluded that the thrust force decreases as increase in feed, since softening of the material due to increment in depth of cut in the work piece causes to enhance the temperature. The effective stress has an almost narrow margin along the center line of the shear zone, while at the cutting edge of the drill bit, effective stress; thrust force and torque are higher than at middle portion of the drilling operation. The results obtained from the finite element analysis (FEA) using Deform-3D are correlating with the results obtained from experimentation.

\section{$5 \quad$ Results obtained from experimentation}

Experiments are conducted by considering five input parameters and measured six responses by selecting $\mathrm{L}_{27}$ orthogonal array from Taguchi's experimental design plan from Minitab@17 software, then to determine the optimal setting of input parameters to obtain multiple performance characteristics of output responses a Grey relational analysis is applied. To identify the most significant parameters from the selected five input parameters in the beginning of the experimentation, an ANOVA is adopted and obtained significant parameters, conducted an experiment called as confirmation experiment to attain optimal output responses [23-27]. The main effect and interaction effect plots are obtain from ANOVA through Minitab@17 software.

\subsection{Results obtained from Grey based Taguchi approach}

Experiments are conducted as per Taguchi $\mathrm{L}_{27}$ orthogonal array and using Grey relational analysis and found an optimal setting of input parameters to obtain multiple performance characteristics of output responses corresponding to larger the grey relational grade. To know the weightage of influencing input parameters over the output responses in level wise, the graphs are drawn between the levels of input parameters versus average grey relational grades. The observations from Fig. 8 reveal that an increase in spindle speed yields decrease in the influence, the effect of feed rate is more at the beginning of the drilling and decreases as the drilling operation progresses and then suddenly increases at the end of the process. Larger the drill diameter more is the influence and lower the point and clearance angles causes more influence on overall output responses during drilling of $\mathrm{Al}-\mathrm{Mg}-\mathrm{Si}$ alloy. 


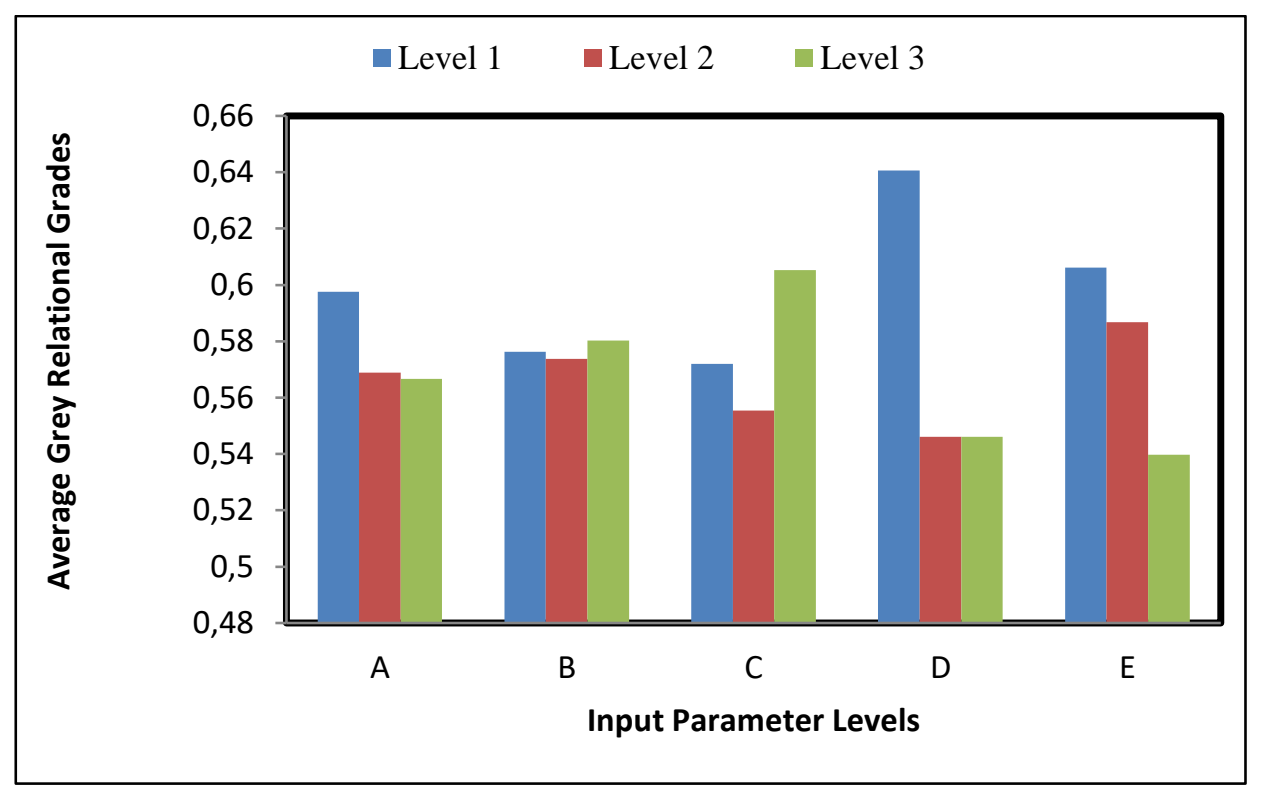

Fig. 8 The weightage of influencing input parameters over the output responses in level wise with reference to average grey relational grades.

\subsubsection{Results obtained from Analysis of Variance (ANOVA)}

The relative importance and statistical significance of the main and interaction effects between process input parameters to influence the output responses are identified from ANOVA in the order of decreasing contribution of each parameter. To test whether the developed hypothesis is correct or not can be known from the obtained statistical data such as $\mathrm{R}^{2}, \mathrm{R}^{2}$ (pred) and $\mathrm{R}^{2}$ (adj) values obtained from Minitab@17 software in the analysis of variance in data means of output responses. From table 10 indicates that the coefficient of determination $\left(\mathrm{R}^{2}\right)$ of the observed responses viz., thrust force and torque proposed approach believed to be sensitive for the variation of input process parameters during drilling of Al-MgSi alloy.

Table 10 Percentage of coefficients of determination $\left(\mathrm{R}^{2}\right)$ of observed responses

\begin{tabular}{|c|c|c|c|}
\hline Output Response & $\mathrm{R}^{2}(\%)$ & $\mathrm{R}^{2}$ adj $(\%)$ & $\mathrm{R}^{2}$ pred (\%) \\
\hline Thrust force & 91.48 & 90.82 & 93.12 \\
\hline Torque & 93.54 & 92.23 & 90.42 \\
\hline
\end{tabular}

Also, it is observed that the torque for $\mathrm{Al}-\mathrm{Mg}-\mathrm{Si}$ alloy believed to be marginal sensitive to the variation of input parameters during drilling. The reason is that the variation in the drill geometry does not interact with other parameters. Consequently, the confirmation test results obtained from ANOVA and the depicted results in the table 10 showed that good agreement of selected input parameters on the observed responses in drilling experiments on $\mathrm{Al}-\mathrm{Mg}-\mathrm{Si}$ alloy.

\subsection{DEFORM-3D analysis for thrust force and torque}

Numerical /FEM analysis of machining with the help of software is very difficult to develop in the recent past; it requires a tailored code and high level of programming skills. Recent developments in the software has shown same advantage to simulate machining operations, to perform simulation by using analysis software, many commercial packages are available. DEFORM-3D is selected among the available packages for analysis during drilling in the present work. The obtained thrust force and torque results from DEFORM-3D are plotted against the time and shown in Fig. 9 during drilling of Al-Mg-Si alloy. The 
observations from the Fig.9 reveal that the thrust force increases from the beginning of the drilling process to middle of the process and then decrease when the drilling operation is over in the drilling of Al-Mg-Si alloy is observed that abrupt change occurred in entire process, the reason may be due to online variation of drill bit geometry.
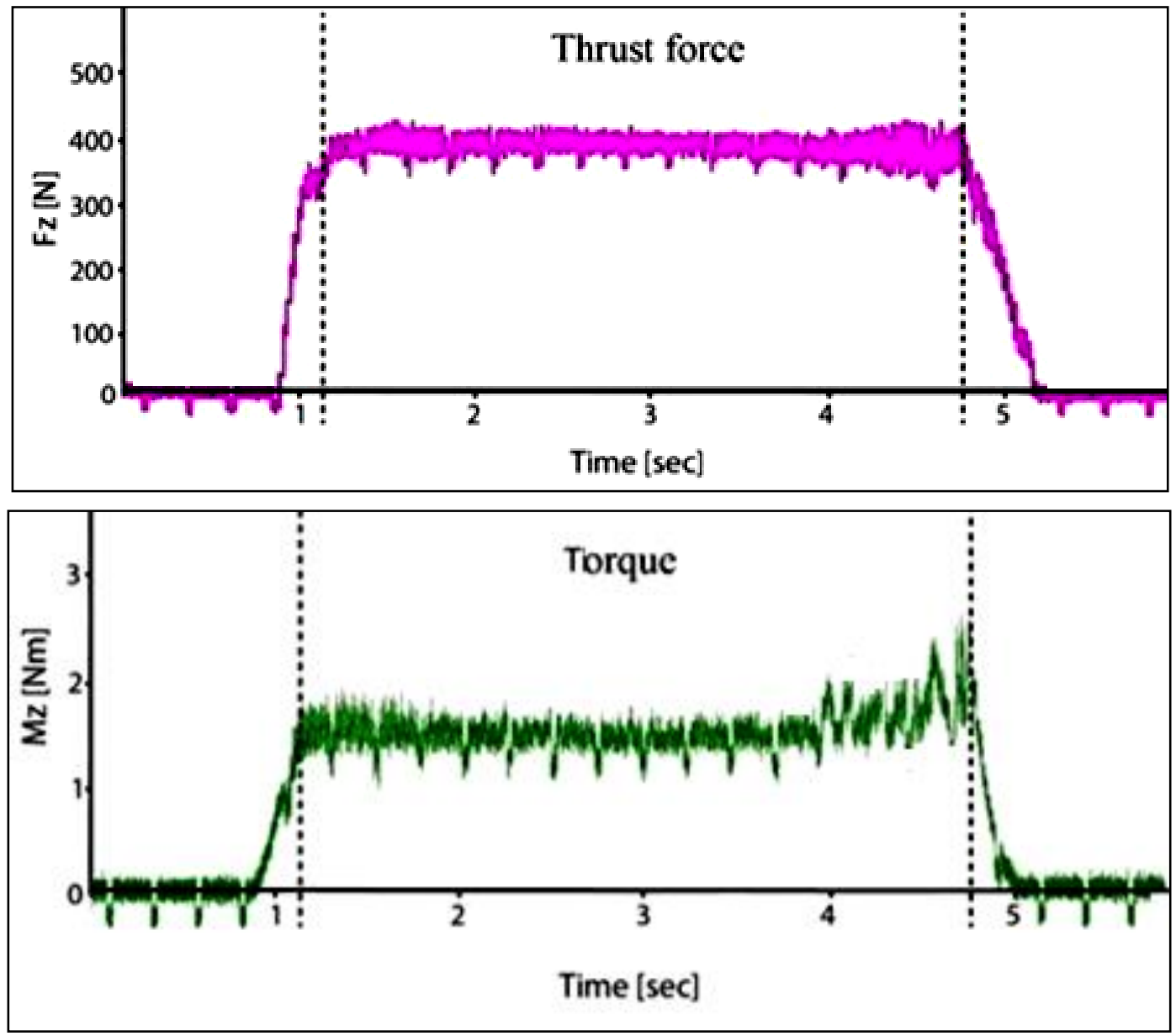

Fig. 9 drill thrust and torque w.r.t increasing simulation steps

From the Fig. 9, the torque variation during drilling of Al-Mg-Si alloy with respect to time is observed that the torque is increased at the start of the drilling due to more friction on cutting edge and then decreased and abrupt changes occurred in entire process, reason may be due to online variation of drill bit geometry.

\subsection{COMPARISION OF RESULTS OF DEVELOPED MODELS}

The present work mainly focused on minimizing of thrust force during drilling of a Al-Mg$\mathrm{Si}$ alloys, in this connection, experiments are conducted and obtained optimal setting of combination of parameters to attain optimum output responses using Grey based taguchi approach. Also simulation models are developed to validate the results in experimentation. The obtained results especially thrust force and torque from the two models viz experimental as well as simulation models are compared with a chosen Al-Mg-Si alloy material and depicted in the Fig. 10. 


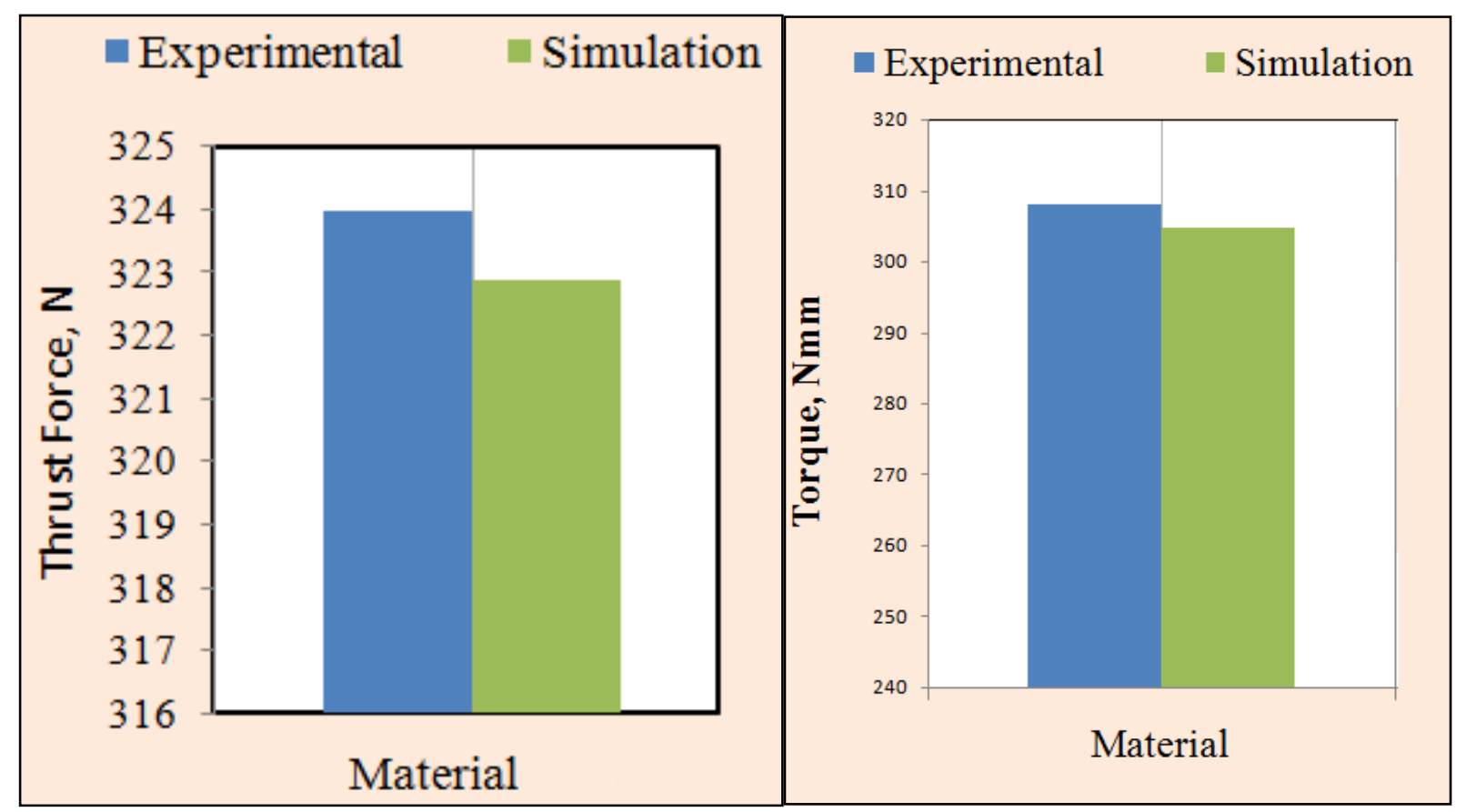

Fig.10 Comparison of experimental and simulation results for thrust force and torque

\section{CONCLUSIONS}

The conclusions obtained from the present work performed to evaluate thrust force and torque during experimentation. The output responses obtained from experimentation using Grey based Taguchi approach are compared with FEM based modelling and simulation performed in DEFORM-3D software are as follows (due to difficulty to simulate for every experiment, in the present work simulation done for randomly i.e., for experiment number.10 because of simulation takes number of days for single experimental conditions)

* The experimental results reveal that the feed rate, point angle and clearance angles are the most influencing parameters on thrust force than the spindle speed and drill diameter for Al-Mg-Si alloy.

* Statistical model deduced from the interaction plots obtained from ANOVA using Minitab@17 software divulges that the combined influence of each input parameter over the other parameters on multiple output characteristic responses. Therefore, the present work confirms that in drilling of Al-Mg-Si alloys for all cutting conditions tested and the thrust force and torque are close to those obtained in drilling experimentation respectively as $16.75 \%$ and $1.06 \%$ in that order mentioned above has been enhanced.

* The simulation results obtained from DEFORM-3D are also in good correlation with that of experimental value (i.e. corresponding to Exp.10) having the percentage variation of $2.4 \%$ for thrust force and almost identical values obtained for torque.

* The temperatures generated during drilling of Al-Mg-Si alloy with HSS twist drill bits are simulated in DEFORM-3D at particular machining condition (i.e. corresponding to Exp.10) is correlating well with the experimental value measured with Infrared Pyrometer at the same machining condition The reason may be that Al-Mg-Si alloy is soft material and total heat generated at the contact of tool and work piece is spread over the top surface of the drilled hole. 
* The effective stress and strain rates are obtained in simulation based on finite element analysis using DEFEORM-3D at a simulation step interval of 2886 is as $216 \mathrm{MPa}$ and effective strain at the rate of $0.461 \mathrm{~mm} / \mathrm{mm}$.

Finally it is concluded that simulation using Deform-3D,which is actually developed based on final element method is more benefitted to implement all categories of alluminium based alloys, found in the areas of automotive, marine, aerospace and ship building industries especially in structural work applications economically without conducting lot of experimental works.

\section{REFERENCES}

[1] Burrs, J. C. A. "Analysis, control and removal CIRP Annals", Manufacturing Technology 58, pp. 519 - 542, 2009.

[2] Gillespie, L. K., Blotter, P. T. "The Formation and Properties of Machining Burrs", Transactions of ASME Journal of Engineers for Industry 98, pp. 66 - 74, 1976.

[3] Wang, G. C., Zhang, C. Y. "Study on the Forming Mechanism of the Cutting- Direction Burr in Metal Cutting”, Key Engineering Materials 259-260, pp. 868 - 871, 2004.

[4] Lauderbaugh L. K. "Analysis of the effects of process parameters on exit burrs in drilling using a combined simulation and experimental approach", Journal of Material Processing Technology 209, pp. 1909 - 1919, 2009.

[5] Davim, J. P.; Reis, P. "Drilling carbon fiber reinforced plastic manufactured by auto clave experimental and statistical study", Materials and Design 24 (5), pp. 315 - 324. 2003.

[6] Kilickap, E. "Modeling and optimization of burr height in drilling of A1-7075 using Taguchi method and response surface methodology", International Journal of Advanced Manufacturing Technology 49, pp. 911 - 923, 2010.

[7] Park, I. W., Dornfeld, D. A. "A Study on Burr Formation Processes Using the Finite Element Method - Part I“, Transactions of ASME, Journal of Engineering Materials and Technology 122, pp. 221 - 228, 2000.

[8] Park, I. W., Dornfeld, D. A. "A Study on Burr Formation Processes Using the Finite Element Method - Part II, The influences of Exit angle. Rake Angle and Backup Material on Burr Formation Processes“, Transactions of ASME, Journal of Engineering Materials and Technology 122, pp. 229 - 237, 2000.

[9] Phadke, M. S. "Quality Engineering Using Robust Design”, Prentice Hall, Englewood Cliffs, New Jersey, 1989.

[10] Tsao, C. C., Hocheng, H. "Evaluation of thrust force and surface roughness in drilling composite material using Taguchi analysis and neural network", Journal of Materials Processing Technology 203 (1-3), pp. 342 - 348, 2008.

[11] Douglas C. Montgomery, "Design and Analysis of Experiments", 5th Edition, John Wiley, 2007.

[12] Ross, P. J. "Taguchi techniques for quality engineering”, McGraw-Hill Book Company, Singapore, 1996.

[13] Taguchi, G. "Introduction to Quality Engineering", Asian Productivity Organization, Tokyo, 1990. 
[14] Bagchi, T. P. "Taguchi Methods Explained - Practical Steps to Robust Design", Prentice-Hall of India, New Delhi, 1993.

[15] Deng, J. L. "Introduction to grey system theory", Grey Syst. 1, pp. 1 - 24, 1989.

[16] Johnson GR and Cook WH. In: Proceedings of seventh international symposium on ballistics, pp. 541 - 547, Netherlands, The Hague, 1983.

[17] Uma Maheshwera Reddy Paturi and Suresh Kumar Reddy Narala, "Constitutive flow stress formulation for aeronautic aluminum alloy AA7075-T6 at elevated temperature and model validation using finite element simulation", Proc IMechE Part L: J Materials: Design and Applications 0(0) 1-11IMechE 2015. DOI: 10.1177/1464420715591860

[18] Reddy, S., Srinivasa Rao, Ch. "Modelling, Simulation and Experimental validation of Burr size in Drilling of Aluminium 6061 alloy", Procedia Manufacturing 20, pp. 458 463, 2018.

[19] Reddy, S. Srinivasa Rao, Ch. "Some investigations on drilling of Aluminium alloys from FEA based simulation using Deform-3D", at $7^{\text {th }}$ international $\& 28^{\text {th }}$ All India Manufacturing Technology, Design and Research (AIMTDR-2018) conference 2018 during $13^{\text {th }}-15^{\text {th }}$ December 2018 organized by College of Engineering Guindy, Anna University, Chennai, 2018.

[20] Reddy, S., Srinivasa Rao, Ch. "Optimization of Machining Parameters during Drilling of Aluminium 2014 Alloy using CATIAV5R19 and DEFORM-3D" Numerical Simulation and Experimental Validation in the proceedings of COPEN 10, 2017 (Paper ID:352) organized by IIT Madras on 07-09 December 2017, pp. 833 - 836, 2017. ISBN: 978-93-80689-28-9.

[21] Tiago Emanuel Fraga da Silva "Numerical Simulation of Metal Cutting Processes on DEFORM-3D software", M.S. dissertation, Faculty of Engineering of the University of Porto, July 2016.

[22] Pawar, P., Ballav, R., Kumar, A. "Modeling and Simulation of Drilling Process in Ti6Al-4V, Al6061 Using Deform-3D Software", International Journal of ChemTech Research 10 (3), pp. 137 - 142, 2017.

[23] Khadar, B. S., Jagannadha, R. M. V., Kolli, M. "Multi-Objective Optimization of Process Parameters for Powder Mixed Electrical Discharge Machining of Inconel X-750 Alloy Using Taguchi-Topsis Approach", Strojnícky časopis - Journal of Mechanical Engineering 71(1), pp.1 - 18, 2021. DOI: 10.2478/scjme-2021-0001

[24] Sejč, P., Bučány, M., Zifčák, P. "Properties of FSW and MIG Welded Joints of AlSiMg Aluminium Alloy", Strojnícky časopis - Journal of Mechanical Engineering 70 (2), pp. 141 - 152, 2020. DOI: $10.2478 /$ scjme-2020-0027

[25] Pawar, P., Kumar, A., Ballav, R, "Parametric Analysis of Electrochemical Discharge Drilling on Soda-Lime Glass Material Using Taguchi L27 Orthogonal Array Method", Strojnícky časopis - Journal of Mechanical Engineering 69 (4), pp. 115 - 132, 2019. DOI: $10.2478 /$ scjme-2019-0047

[26] Ramanaiah, N. "Optimization of Process Parameters for FSW of Al-Mg-Mn-Sc-Zr Alloy Using CCD And RSM", Strojnícky časopis - Journal of Mechanical Engineering 68 (3), pp. 195 - 224, 2018. DOI: 10.2478/scjme-2018-0035

[27] Himanshu, P., Lalta, P., Mayank, P., Vineet, T. "An Estimating the Effect of Process Parameters on Metal Removal Rate and Surface Roughness in WEDM of Composite 
Al6063/SiC/Al ${ }_{2} \mathrm{O}_{3}$ by Taguchi Method", Strojnícky časopis - Journal of Mechanical Engineering 67 (2), pp. 25 - 36, 2017. DOI: 10.1515/scjme-2017-0015 